\title{
Entrevista com Lená Medeiros de Menezes
}

\author{
Amanda André Mendonça* \\ Pâmella Santos dos Passos**
}

Professora Emérita da Universidade do Estado do Rio de Janeiro (UERJ), Titular de História Contemporânea e Pesquisadora Visitante do Programa de Pós-graduação em História da mesma Universidade, tendo recebido, no ano de 2015, a medalha da Ordem de Mérito José Bonifácio da UERJ e o título de Grão-Mestre da referida Ordem. É Doutora em História Social pela USP (1995), com Pós-doutorado na PUC-SP (2007), Mestre em História Social das Idéias pela UFF (1985), Especialista em História da América pela UFF (1983) e Licenciada em História pela UERJ (1969). Entre janeiro de 2008 e julho de 2015 ocupou a função de Sub-reitora de Graduação da UERJ e foi coordenadora institucional do Programa Ciência Sem Fronteiras. Foi responsável pela elaboração de projeto e implantação do Mestrado e do Doutorado em História na UERJ, sendo a primeira coordenadora do Programa (1995), coordenadora geral por mais dois mandatos (20002002 e 2002-2004) e coordenadora do curso de Doutorado (2004-2006), pertencendo, desde 1995, ao quadro permanente do Programa. Tem larga experiência de docência e pesquisa na área de História, dedicando-se à investigação das seguintes temáticas: movimentos migratórios, imigração urbana (ênfase ao Rio de Janeiro e às imigrações francesa e portuguesa), expulsão de estrangeiros, movimento operário, anarquismo, prostituição e tráfico internacional de mulheres, estudos de gênero, imprensa e discurso midiático, imagens e representações, relações internacionais. Dentre os livros publicados, destacam-se um premiado pelo Arquivo Nacional e dois outros que se tornaram referência nos estudos sobre expulsão de estrangeiros e sobre imprensa, revolução e representações. Escreveu inúmeros artigos e capítulos de livros publicados no Brasil e no exterior, com destaque para Portugal, Espanha e França. Coordena o Laboratório de Estudos de Imigração (LABIMI), vinculado aos Programas de Pós-graduação em História e de Relações Internacionais da UERJ. Foi agraciada com Moção de Congratulações pela Assembleia Legislativa do Rio de Janeiro, no ano de 2009 e pela Câmara dos Vereadores do Rio de Janeiro em 2019, por suas contribuições ao ensino e à cultura. É Sócia efetiva do Instituto Histórico e Geográfico do Rio de Janeiro

\footnotetext{
* Pós-doutoranda em educação, doutora em Política Social, mestre em educação pelo Programa de Pós Graduação em Educação - PPGE / UFRJ. Tem experiência na área de Sociologia da educação, atuando principalmente nos seguintes temas: sociologia da educação, gênero, educação, laicidade e Políticas Públicas. Foi professora substituta da Faculdade de Educação da Universidade Federal do Rio de Janeiro e tutora do CEDERJ. Atualmente é docente na Universidade Estácio de Sá e integra o Observatório da Laicidade na Educação - OLÉ. E-mail: amandademendonca@gmail.com ORCID: http://orcid.org/0000-00033324-5672

** Professora do quadro efetivo do Instituto Federal de Educação Ciência e Tecnologia do Rio de Janeiro (IFRJ). Atualmente realiza estágio de Pós Doutorado no Programa de Pós Graduação em Educação da Universidade Federal Fluminense (UFF) Com estágio de Pós Doutorado pelo Programa de Pós graduação em Antropologia Social/ Museu Nacional/ Universidade Federal do Rio de Janeiro (2016). Doutora em História Social pela Universidade Federal Fluminense (2013), mestre em História, área de concentração História Política, pela Universidade do Estado do Rio de Janeiro(2008) e graduada em História pela Universidade do Estado do Rio de Janeiro(2006), Possui experiência na área de História e Ensino de História, com ênfase em História do Brasil República. Desenvolveu pesquisas sobre Juventudes, Cultura Popular e Favelas Cariocas, Anticomunismo no Brasil, Ensino de História em Escolas Técnicas. Atualmente pesquisa sobre os impactos do Conservadorismo no Ensino de História e coordena projetos de extensão na área de Educação e Direitos Humanos. E-mail: pamella.passos@ifrj.edu.br ORCID: https://orcid.org/0000-0001-9759-6100
} 
(IHGRJ) e ocupa a Presidência da instituição desde dezembro de 2019.

1) Como professora Emérita da Universidade do Estado do Rio de Janeiro (UERJ) e Titular de História Contemporânea, como a senhora analisa a relação entre Discursos Conservadores e Direitos Humanos ao longo da chamada Idade Contemporânea?

Lená Medeiros de Menezes: Ainda que admita variações concernentes ao espaço-tempo, que relativizam, muitas vezes, sua dimensão liberal, o pensamento conservador pode ser caracterizado como aquele que se coloca em defesa das tradições, principalmente as relativas à família, religião, usos, costumes e convenções sociais. Nesse sentido, ele combate toda e qualquer mudança revolucionária, ou seja, aquela que implica subversão da ordem.

Os discursos conservadores têm sempre uma configuração preservacionistas, apresentando-se como instrumento de combate contra toda e qualquer mudança que afeta, na raiz, os padrões político econômicos, sociais e culturais estabelecidos, expressos, de forma contundente, na tríade Pátria, Família e propriedade.

Considerada essa conformação, torna-se incompatível com a defesa de direitos humanos surgidos no bojo de movimentos populares que advogam direitos iguais para grupos que estavam, tradicionalmente, “à margem”, como LGBTIs, negros, ciganos e outros, acrescentando-se o direito da mulher de dispor de seu próprio corpo, que se choca com o patriarcalismo secular e com preceitos religiosos, em uma época de ressurgimento de muitos fundamentalismos.

No caso específico dos imigrantes, os discursos conservadores caminham no sentido da defesa dos direitos de exclusividade sobre um determinado território, que conformam uma nação idealizada, ameaçada por aqueles que vêm de fora e, em última instância, ameaçam as tradições; razão pela qual o multiculturalismo também não é bem-vindo.

Recuando-se no tempo, deve ser lembrada a longa duração do discurso de combate a direitos que apontavam para a igualdade social, econômica ou de raça ou gênero. Um exemplo foi a luta pelo direito ao voto feminino, em uma democracia desigual em termos de gênero, o que gerou verdadeiras batalhas campais com a polícia. Muitos outros exemplos poderiam ser citados em uma contemporaneidade alargada; caso da luta pelo divórcio, pela abolição da escravatura e outros; mudanças que só puderam ser incorporadas, regra geral, de forma lenta e gradual, excetuando-se o caso das revoluções, embora nem todas libertadoras para alguns grupos.

Considerados os tempos em que vivemos, no Brasil, a grande tragédia é que os discursos conservadores voltam-se para a negação da democracia (sua defesa é apenas retórica), para o negacionismo (que ridiculariza a ciência) e para o combate irracional, de fundo religioso - não apenas neopentecostal - ao aborto e à liberdade sexual, com glorificação de tempos passados e repúdio à necessidade de mudanças em direitos emanados do igualitarismo. Afinal, liberal em sua origem, o discurso conservador sempre se contrapôs ao discurso pela igualdade entre os seres humanos, base da defesa dos direitos humanos, essencialmente revolucionário.

2) Especialista em História da América pela Universidade Federal Fluminense, que contextos históricos em nosso continente, a senhora destacaria para analisar as tensões entre conservadorismos e direitos humanos?

Lená Medeiros de Menezes: Em uma análise de longa duração, é possível dizer que a América Latina pode ser considerada um laboratório da alternância entre governos de esquerda ou à es- 
querda, caracterizadas por um avanço na defesa dos direitos humanos, e governos conservadores, que aprofundam os discursos de preservação da ordem e dos padrões sociais tradicionais, em geral, relativos à família, à religião e aos costumes, bem como no sentido de uma economia liberal, não voltada para o bem comum.

No enfoque dos direitos humanos, alternam-se, por seu turno, momentos de conquistas e de retrocessos, ou, pelo menos, de estancamentos. É certo que diferenças marcantes afetam os diferentes países, sujeitos a conformações e circunstâncias muito diferenciadas. Só podemos comparar, "a grosso modo", por exemplo, o movimento negro ao indígena, tendo por referência, no último caso, o caso mexicano e a luta encaminhada a partir do movimento de Chiapas, que se distancia, por sua vez, de outros tantos movimentos.

3) Com reconhecida produção acadêmica sobre estudos migratórios a senhora chama atenção para aqueles que são os "Indesejáveis". Como tal categoria foi criada e revisitada ao longo da História do Brasil e que usos políticos foram feitos dela?

Lená Medeiros de Menezes: Indesejáveis foi um termo que ganhou grande visibilidade na Primeira República e dizia respeito aos imigrantes que, por diferentes razões, eram considerados perigosos aos interesses da República e/ou nocivos à sociedade. O combate a eles ensejou a expulsão do Brasil de estrangeiros anarquistas, comunistas, bem como de desordeiros e criminosos variados: dos vadios e vagabundos aos gatunos, ladrões, vigaristas, caftens (traficantes de mulheres para prostituição) e vendedores/traficantes de droga (a partir de 1919).

No tempo presente, em um enfoque internacional, continuam a ser indesejáveis aqueles que, desesperados, cruzam o oceano, arriscando suas vidas; escalam muros e cercas; marcham quilômetros, em busca de um lugar que lhes possa oferecer abrigo e/ou melhores condições de vida, impossíveis em suas terras natais. $\mathrm{Na}$ defesa dos direitos exclusivos sobre o solo, os diferentes países fecham os olhos aos direitos humanos, tendendo a ver naquele "outro" que chega um elemento pernicioso e perigoso, capaz de solapar suas conquistas e direitos, ensejando, ademais, uma xenofobia que caminha ao encontro dos neofascismos. Longe se encontra, portanto, a utopia do multiculturalismo que, pensavam, substituiria o Estado-nação, que vem se fortalecendo, justamente, no embate com a imigração.

Ampliada a possibilidade do uso do conceito de forma mais ampla, é possível dizer que, ao longo da História, houve invenção de indesejáveis, caracterizados como o “outro" transformado em inimigo (externo ou interno) que, por trazer prejuízos à a ordem estabelecida, deve ser combatido, quando não aniquilado. Nesse caso, defesa da "ordem", máxima no pensamento e discurso conservadores, torna-se defesa contra o "estrangeiro", palavra repleta de significados de exterioridade.

Considerando-se o caso brasileiro e a conjuntura que atravessamos, nesses idos de 2020, têm sido considerados “indesejáveis” não só criminosos (com variações de grau), mas, principalmente, opositores e militantes políticos (com predileção para comunistas, reais ou não), ateus, gays e transsexuais, pobres, favelados, negros, velhos, etc.

4) Como pesquisadora e orientadora de um Programa de Pós-graduação em História com ênfase em História Política, como a senhora percebe o limiar entre a Historiografia e as Relações Internacionais, quais são os desafios para a produção historiográfica? 
Lená Medeiros de Menezes: História e Relações Internacionais constituem campos diferentes de saber. As RI, embora contem com teorias próprias, é um campo interdisciplinar, envolvendo aportes políticos, históricos, econômicos, jurídicos e diplomáticos. Em termos históricos, dialogam permanentemente com a História Contemporânea, embora, a maioria dos professores e pesquisadores da área considerem a importância maior da Ciência Política, influenciados pela conformação norte-americana das RI. Por outro lado, há que ser considerada a existência da História das Relações Internacionais, de origem francesa, que teve Pierre Renouvin como inspiração e nomes como Jean-Baptiste Duroselle, Robert Frank e outros.

Entrei no departamento de História da UERJ como professora de Relações Internacionais, para assumir turmas do Prof. Fernando Sgarbi Lima, inspirada na Escola Francesa. Há pouco tempo, um doutorando do Instituto Pierre Renouvin, em Paris, fez contato comigo, pois tinha observado, em suas pesquisas, essa influência na UERJ, ligada ao meu nome, razão pela qual me entrevistou, para que eu contasse minha experiência e, principalmente, como tinha chegado a Renouvin.

Infelizmente, uma mudança curricular no curso de História da UERJ, realizada em nos anos 1980, eliminou a disciplina do currículo, negando a especificidade das Relações Internacionais e dispersando os conteúdos em História Contemporânea III. Acredito que o curso perdeu muito com isso.

Em minha trajetória, costumo me definir como uma profissional que transita na fronteira entre História e Relações Internacionais. Por isso fui chamada a compor o quadro docente dos dois programas de Pós-graduação na UERJ. É interessante notar que, dentre os estudantes nos dois cursos, o interesse pela temática das migrações é maior em RI do que na História, talvez por sua contemporaneidade.

Tenho grande alegria de ter estado inserida no processo que tanto criou o Programa de Pós em RI - que guardou relações com o Curso de Especialização em RI, quanto com a linha de pesquisa do Programa de História -, quanto a Graduação. Nos dois casos fui relatora da proposta de sua criação no Conselho Superior de Ensino, Pesquisa e Extensão e, no caso da Graduação, era eu, então, Sub-reitora de Graduação e acompanhei e incentivei, de perto, a proposição e elaboração do projeto.

5) Em sua tese para professora Titular, recentemente publicada pela editora Ayran sob o título "Tramas do Mal: Imprensa e discursos de combate a Revolução de (1917-1921), a senhora lança mão de uma análise discursiva para realização de uma investigação histórica. Como a Análise do Discurso contribui nos estudos históricos?

Lená Medeiros de Menezes: O livro evoluiu da tese apresentada ao Concurso para Professor Titular de História Contemporânea, revista e acrescida de um capítulo sobre o conceito de revolução.

A inspiração inicial para propor o desafio de me lançar à escrita da Revolução de Outubro, a partir das formas pelas quais ela foi noticiada, foi Marc Bloch, ao proclamar que não bastava que o historiador estudar processos e fatos, mas, também, as formas pelas quais os contemporâneos o percebiam.

É interessante dizer que o trabalho foi não só inédito em 2000, quando foi apresentada ao concurso, quanto continua a sê-lo. Além disso, mostra uma contemporaneidade impressionante, mesmo tendo-se passado 20 anos, não só em termos da ocorrência de representações míticas na 
imprensa quanto do discurso anticomunista que se coloca na base das políticas de combate conduzidas por grupos - e governos - de extrema direita. Tenho orgulho em dizer que o trabalho, ao longo do tempo em que ele "descansou" (imagem criada por minha irmã Leila), serviu de inspiração a trabalhos sobre outras revoluções e, nos dias de hoje, permanece como referência tanto temática quanto metodológica.

Quanto ao uso de técnicas da análise de discurso, creio que foi uma escolha acertada. Ao escolher caminhos para a formulação do trabalho, percebi, desde o início, que a História não teria uma metodologia capaz de me possibilitar tratar devida e profundamente as matérias jornalísticas, escolhidas como fontes. A análise de texto, nesse contexto, ao se deter no objeto material que é o texto, também limitava minhas análises. Foi assim que optei por trabalhar com a $\mathrm{AD}$, segundo a "escola" francesa, tendo por referência básica as obras de Charaudeau, especialmente seus textos sobre informação midiática.

É certo que foi um grande desafio, pois tive que adaptar caminhos, nos quais, ademais, auxiliaram-se as obras de Delumeau e Girardet, à medida em que caminhei para a análise do mito e das constelações míticas.

Em termos das contribuições para a História, determinadas técnicas de AD possibilitam observar aspectos do discurso que acabam escapando à atenção do historiador, como, por exemplo, o uso dos tempos verbais, a utilização da indeterminação do sujeito, o recurso às figuras de linguagem - com destaque para a metáfora e a hipérbole -, e o recurso às "palavras de força", o que não guarda relação com o simples contar palavras das fases iniciais que marcaram o olhar do historiador sobre o linguístico. Ou seja, a todo momento, a AD, como nos diz Charaudeau, permite ao historiador o diálogo entre o intra e o extra-discursivo, essencial nos trabalhos sobre informação/propaganda midiática.

6) Ainda sobre seu livro "Tramas do Mal: Imprensa e discursos de combate a Revolução de (1917-1921), percebemos a construção de um discurso anticomunista no Brasil já na Primeira República. Como este discurso aparece ao longo da República até os dias atuais? Poderíamos compreendê-lo a partir de uma cultura política de construção de medo e criação de inimigos?

Lená Medeiros de Menezes: O discurso anticomunista é recorrente ao longo da República e é possível dizer que ele acompanhou o regime ao longo de todo o século XX, sendo ressignificado, mais uma vez, no tempo presente. É possível dizer que este discurso permeou nossa cultura política republicana autoritária, propensa sempre a desvelar e criar inimigos para combater. Latente ao longo do tempo, o discurso emergiu, com grande força e visibilidade, em algumas conjunturas.

De forma geral, é possível considerar que foi implantado antes mesmo de 1917, no combate ao anarquismo libertário ou anarquismo-comunismo, embora a ênfase repousasse no anarquismo e não no comunismo. Foi, porém, a partir da Revolução Bolchevique que ele ganhou força, despontando, com grande visibilidade na imprensa, a partir do momento em que Lênin tirou a Rússia da guerra, o que foi propagado, pelos aliados, como "a grande traição". A partir de então o comunista, assumiu o papel de inimigo a ser vigiado, combatido e aniquilado. Essa política de combate foi marcante no governo Artur Bernardes e depois, com Getúlio Vargas, estando na base do golpe que levou ao Estado Novo.

A redemocratização no imediato pós-1945 arrefeceu um pouco o combate, inclusive com a legalização do partido comunista no Brasil, mas isso durou pouco e, à medida que a Guerra Fria 
se aprofundou, o discurso voltou a circular com força, principalmente na virada dos anos 1960 para 1970, quando a guinada comunista da Revolução Cubana transferiu o espectro da Guerra Fria para as Américas, como demonstra o trabalho da Pâmella Passos.

O golpe civil-militar no Brasil, como os golpes que solaparam a América Latina, teve no combate ao comunismo seu sentido e sua justificativa, apresentando o mundo - e o Brasil - como um mundo ameaçado por uma conspiração "maligna e maléfica", movida por um inimigo que deveria ser combatido a todo custo. É essa visão de mundo que ressurge agora, ainda que "fora do lugar", pois, pela primeira vez, o discurso anticomunista toma formas agressivas em um período democrático, pelo menos, juridicamente falando.

7) A conjuntura atual vem sendo marcada por uma crescente ascensão de discursos conservadores a esferas de poder/governança, em consonância com este movimento percebese um recrudescimento de ataques a produção intelectual, em especial, a produção historiográfica. Pesquisas históricas revisionistas estão sendo usadas para legitimar negacionismos. A senhora poderia diferenciar revisionismo histórico de negacionismo histórico pontuando o compromisso do ofício do Historiador, sobretudo, em períodos conversadores?

Lená Medeiros de Menezes: Tomando-se o conceito de revisionismo pela raiz, é certo que a História está sujeita a um continuado revisionismo. Aliás, dizia o Prof. Fernando Sgarbi Lima, a quem reputo o papel de meu guru, que sempre que um processo ou fato histórico parecia esgotado era sinal de que ele havia sido pouco estudado; com o quê concordo plenamente. A palavra revisionismo, entretanto, vem sofrendo "deslizamentos", para usar um termo de AD, aproximando-se do negacionismo, nessa absurda formulação de marxismo cultural, que vê o comunismo enraizado nas Universidades e nos organismos culturais.

Nessa "guerra cultural", não é surpreendente que a História e os historiadores se tornem alvos privilegiados. Negar a História até aqui escrita e, com o olhar dirigido para o golpe e a ditadura militar, propor a escrita de uma outra História tornou-se "missão" a que se atribuem alguns ressentidos da democratização e saudosistas da ditadura, que abraçam um negacionismo que anda de mãos dadas com o irracionalismo, ressuscitando o espectro de tempos de queima de livros (tomara que apenas simbolicamente) e de pessoas. É estarrecedor que, na base da junção da CAPES e do $\mathrm{CNPq}$ esteja a censura e a interdição a determinadas pesquisas e um verdadeiro massacre às Ciências Humanas, incluída a História.

Nesse quadro, a responsabilidade dos historiadores não é só de resistência, mas de inovação na proposição de intervenções contradiscursivas. Há muito a História perdeu-se na fragmentação de um micro-olhar que se tornou alienado e alienante, com o abandono das análises macro, que priorizavam relações que acabaram por se perder. É necessário que estes rumos sejam corrigidos, tão quanto é importante que o homem "comum" saiba, pelos meios possíveis, que a História se faz com método e fontes e não é obra de amadores, principalmente quando estes negam o valor da ciência e, portanto, do método científico, apostando em formas obscurantistas de dominação. 